\title{
PENGARUH LATIHAN BOX DRILL TERHADAP KEMAMPUAN SMASH BOLA VOLI
}

\author{
Zuhar Ricky \\ (Universitas Dharmas Indonesia) \\ zuharricky@gmail.com
}

\begin{abstract}
Abstrak
Latar belakang penelitian ini karena rendahnya kemampuan smash bola voli pemain bola voli SMAN 1 Baso Kabupaten Agam. penelitian ini bertujuan untuk mengetahui pengaruh latihan box drill terhadap kemampuan smash. Sampel dalam penelitian ini berjumlah 32 orang pemain putera SMAN 1 Baso Kabupaten Agam. Peneliti menggunakan intrumen tes kemampuan smash diagonal dan frontal. Pendeskripsian data dan pengujian hipotesis digunakan adalah statistik deskriptif dan inferensial yaitu rumus uji t, pertama kali peneliti melakukan uji normalitas, setelah itu dilakukan uji homogenitas, dan dilanjutkan dengan uji t. Uji t bertujuan untuk menguji perbedaan ratarata sampel yang di ambil dari populasi kelompok yang normal dan homogen. Dari hasil perhitungan uji-t kelompok yang dilakukan perlakuan yaitu latihan box drill berpengaruh signifikan terhadap kemampuan smash bola voli dengan nilai t hitung 13,04 dan t tabel 2,04 .
\end{abstract}

Kata Kunci: Latihan Box Drill, Kemampuan Smash, Bola Voli.

\section{EFFECT OF PLYOMETRICS TRAINING AND SELF CONFIDENCE TOWARDS THE ABILITY OF SMASH VOLLEYBALL}

\begin{abstract}
This study is attracted because of the low volleyball smash ability of volleyball players at the SMAN 1 Baso, Agam Regency. This study aims to determine the effect of the box drill training on smash skills. The sample in this study amounted to 32 male players from the SMAN 1 Baso, Agam Regency. The Researcher employed the test instrument for diagonal and frontal smash abilities. The data description and hypothesis testing used were descriptive and inferential statistics, namely the t-test formula. The researcher first conducted a normality test, the homogeneity test was then performed and continued with the $t$-test. The t-test aims to examine the difference in the average sample taken from a normal and homogeneous population group. Based on the results of the calculation of the group t-test carried out treatment using the box drill training, it shows a significant effect on the ability of volleyball smash with the $t$ value of 13.04 and t table 2.04.
\end{abstract}

Keywords: Box Drill Training , Smash Ability, Volleyball

Correspondence author: Zuhar Ricky, Universitas Dharmas Indonesia, Indonesia. E-Mail: zuharricky@gmail.com

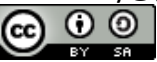


Jurnal Halaman Olahraga Nusantara licensed under a Creative Commons Attribution-ShareAlike 4.0 International License.

\section{PENDAHULUAN}

Pembinaan olahraga merupakan salah satu upaya untuk meningkatkan kualitas manusia Indonesia, yang pada dasarnya bertujuan pada peningkatan kesehatan jasmani, mental dan rohani masyarakat serta membentuk watak, kepribadian, disiplin dan sportifitas yang tinggi. Hal ini dapat meningkatkan prestasi yang dapat menumbuhkan rasa nasionalisme antara sesama manusia. Apabila aspek-aspek tersebut berkembang berselaras maka akan timbul kehidupan yang harmonis dalam pertumbuhannya.

Olahraga merupakan salah satu upaya dalam meningkatkan kualitas sumber daya manusia, sehingga pemerintah menjadikan olahraga sebagai sarana Pembangunan Nasional. Hal ini dapat dilihat dalam pasal 25 ayat 4 UndangUndang Nomor 3 Tahun 2005 tentang sistem Keolahragaan Nasional bahwa: Keolahragaan nasional bertujuan memelihara dan meningkatkan kesehatan, kebugaran, prestasi, kualitas manusia, menanamkan nilai moral dan akhlak mulia, sportivitas, disiplin, mempererat dan membina persatuan dan kesatuan bangsa, memperkokoh ketahanan nasional, martabat, dan kehormatan bangsa. Banyak hal yang harus dilakukan agar memiliki badan sehat dan bugar dengan berolahraga di lingkungan sendiri, seperti di rumah, sekolah, dan lain-lain.

SMA Negeri 1 Baso Kabupaten Agam mengembangkan kegiatan ektrakurikuler diantaranya pada bidang olahraga yaitu seperti futsal, bola voli dan lain sebagainya. Dengan adanya kegiatan ektrakurikuler ini akan mampu menggali bakat-bakat yang ada pada anak-anak. Banyak dari anak-anak yang ingin belajar olahraga diantaranya bola voli tapi kurang memahami basic dari permainan ini, karena banyak anak-anak tidak dibimbing atau diarahkan ketika mereka duduk di bangku Sekolah Dasar (SD) sampai dengan Sekolah Menengah Atas (SMA).

SMA Negeri 1 Baso Kabupaten Agam adalah sekolah yang membina kegiatan olahraga bola voli dengan harapan bisa mencetak para pemain yang bisa berbicara banyak pada ajang yang bergengsi seperti POPDA, PORPROV, 
PORWIL, PON, Bahkan mencapai kompetisi tertinggi di Indonesia bahkan luar negeri, dengan adanya prestasi dari siswa akan membuat harum nama sekolah serta nama daerah. Untuk meraih prestasi tersebut dibutuhkan keseriusan dari siswa itu sampai dengan pihak sekolah. Itu semua tidak mungkin tercapai apabila tidak dikombinasikan dengan latihan yang serius dan sungguh-sungguh sehingga mendapatkan skill yang diinginkan yaitu skill dalam permainan bola voli (Radcliffe, 2013).

Zaman teknologi seperti sekarang ini memudahkan kita dalam menggali ilmu, informasi yang nantinya dapat digunakan oleh orang-orang tidak terkecuali siswa sekolah, supaya dapat bermain bola voli yang baik sangat dibutuhkan sekali basic skill diantara fisik, teknik, taktik, mental. Persiapan ini sangatlah penting demi menggapai suatu prestasi yang diinginkan. (Sugarwanto \& Okilanda, 2020). Apabila persiapan yang dilakukan kurang baik juga akan berpengaruh kepada prestasi. Diantara aspek di atas yang merupakan faktor utama adalah kondisi fisik. Menurut (Syafruddin, 2011) menyatakan demi memperbaiki suatu prestasi tidak terlepas dari latihan, istirahat, gizi, dukungan dari pihak lain sehingga latihan yang dilakukan lebih bermakna dan bermanfaat .

Aspek basic skill yang akan di kaji yaitu teknik dalam permainan bola voli yaitu smash, karena smash adalah kunci menciptakan poin yang banyak demi menuju kemenangan, pukulan smash yaitu pukulan keras yang dapat menghasilkan angga, (Winarno, 2013), namun selama ini pemain bolavoli SMA Negeri 1 Baso belum menampakkan hasil yang memuaskan dalam permainan bola di daerahnya sendiri. Selama ini kemungkinan penyebab performa pemain tidak optimal yaitu kondisi fisik yang menurun. Performa yang tidak optimal juga dapat terjadi karena pemain mengalami kecemasan yang berlebihan saat latihan serta pertandingan, konsentrasi menurun sehingga teknik yang dikuasai pun menjadi berkurang. Selain itu pemain yang tidak optimal pada saat pertandingan juga dapat disebabkan oleh kurangnya rasa percaya diri yang mereka miliki. Pemain tidak yakin akan kemampuan yang dimilkinya, sehingga kurang mampu menghadapi tekanan dari lawan serta penonton (Sole, 2018) 
Beranjak dari kenyataan yang dijumpai penulis di lapangan pada pemain bolavoli SMA Negeri 1 Baso Kabupaten Agam, banyak pemain yang kurang bersemangat dalam mengikuti latihan dan kondisi fisik yang menurun. Kadangkadang mereka juga malas mengikuti proses latihan, dengan berbagai alasan seperti sakit, tidak enak badan, kecapekan dan lain-lain. Yang mungkin di sebabkan oleh faktor sarana prasarana yang kurang memadai ataupun motivasi pelatih serta pemain yang kurang pada saat latihan (Sole, 2018).

Faktor lingkungan juga sangat mempengaruhi pergaulan pemain sehingga dapat berakibat terhadap hasil latihan yang tidak maksimal. Menurut (Sarjono \& Sumarto, 2010) ada dua sasaran latihan yaitu aspek fisik dan aspek mental. Aspek fisik untuk peningkatan kemampuan dari setiap individu, sedangkan mental untuk membentuk karakter seperti, tanggung jawab, kerja keras, disiplin, jujur, saling menghormati, menghargai dan lain sebagainya. Melihat kenyataan itu maka penulis sangat ingin mengetahui secara nyata apa benar adanya pengaruh rasa percaya diri terhadap peningkatan prestasi pada pemain bolavoli SMA Negeri 1 Baso Kabupaten Agam.Selain kondisi fisik, teknik, taktik, mental, latihan juga merupakan salah faktor yang dapat mempengaruhi pemain,.

Gushendra \& Iqbal (Nur et al., 2017) menyatakan bahwa Khusus mengenai latihan power otot tungkai diperlukan metode latihan khusus dan berbeda dengan latihan kondisi fisik lainnya. Apabila cara dan variasi latihan yang digunakan kurang tepat maka hasil yang diinginkan tidak maksimal. Kondisi seperti inilah yang mesti menjadi fokus utama dalam latihan, agar variasi yang digunakan oleh guru beserta tenaga pendidik lainnya maka akan tercapai suatu yang diinginkan yaitu prestasi yang tinggi dari siswa. (Stojanović, Ristić, McMaster, \& Milanović, 2016).

Berdasarkan pengamatan di lapangan peneliti sebagai mantan pemain bolavoli putera dan menurut informasi yang diperoleh dari pelatih dan pengamatan langsung yang peneliti lakukan yaitu pemain bola voli SMA Negeri 1 Baso Kabupaten Agam tidak mampu bermain dengan baik sesuai yang diharapkan oleh pelatih, ini terlihat dari pertandingan dan uji coba yang dilakukan sering mengalami kekalahan, serta jarang sekali mendapatkan juara pada suatu 
kompetisi. Selain itu sering pemain SMA Negeri 1 Baso Kabupaten Agam tidak terpilih menjadi pemain POPDA serta pemain PORPROV.

Fundamental basic dalam permainan bola voli diantaranya passing, servis, defense, bloking, dan smash. Diantara teknik tersebut smash menjadi hal yang sangat diperhatikan guru atau pelatih karena dapat menghasilkan angka yang banyak. Smash merupakan suatu upaya yang dilakukan seseorang spiker dengan cara memukul bola dengan lompatan diiringi tamparan talapak tangan pada bola secara kencang. Dalam melakukan smash pemain harus mempunyai koordinasi yang baik seperti, timing, cara melompat, langkah, mata dan tangan sehingga smash yang dihasilkan bisa diarahkan sesuai kemauan dari si pemain tersebut Robinson (Pranopik, 2017). Smash merupakan basic yang sukar untuk dipelajari karena teknik yang dilakukan harus melompat di udara supaya bisa mempertahankan badan berhenti sejenak. Kemampuan smash adalah salah satu teknik yang sukar dan menjadi perhatian dari pelatih dibandingkan dengan teknikteknik lainnya.

Sejauh pengamatan peneliti di lapangan kendala yang sering dijumpai oleh setiap pemain saat bertanding dan latihan yaitu sering mengalami kesulitan untuk melakukan smash. Hal ini terlihat dari smash yang dilakukan sering tidak melewati net, bola yang dismash tidak tepat dan keluar lapangan. Hal ini diduga mempunyai pengaruh yang berarti terhadap latihan dan rasa percaya diri dari pemain. Namun dalam hal ini belum pernah dilakukan penelitian terhadap bentuk latihan tehadap peningkatan kemampuan smash pemain, sehingga belum diketahui bentuk latihan mana yang baik terhadap peningkatan kemampuan smash pemain.

Namun pada kesempatan ini penulis menduga kurangnya kemampuan loncat pemain yang disebabkan oleh bentuk latihan yang belum baik. Sesuai dengan data yang telah dijelaskan maka peneliti ingin melihat pengaruh bentuk latihan terhadap kemampuan smash pemain bolavoli SMA Negeri 1 Baso Kabupaten Agam sesuai dengan susunan program latihan yang sistematis dan terencana. 


\section{METODE}

Penelitian ini merupakan penelitian eksperimen (Sugiyono, 2016) mengatakan bahwa penelitian eksperimen yaitu untuk melihat dampak dari latihan box drill (variabel bebas) kemampuan smash (variabel terikat). Populasi pada penelitan ini ialah siswa SMA Negeri 1 Baso Kabupaten Agam yang mengikuti kegiatan ektrakurikuler olahraga bola voli. Populasi terdiri dari 1 tingkatan yaitu usia 16 sampai 19 tahun dengan total 59 orang, 32 siswa putera dan 16 orang siswa Puteri. Pengambilan sampel dilakukan menggunakan purposive sampling yaitu "penentuan dilandasi tujuan atau pertimbangan-pertimbangan tertentu". Sampel diambil sebanyak 32 orang pemain bola voli SMA Negeri 1 Baso yang terdiri atas pemain putera saja.

Tabel 1. Distribusi Pemain Bola Voli SMA Negeri 1 Baso

\begin{tabular}{ccc}
\hline $\begin{array}{c}\text { Pemain } \\
\text { putera }\end{array}$ & $\begin{array}{c}\text { Pemain } \\
\text { Puteri }\end{array}$ & Jumlah \\
\hline 32 Orang & 16 Orang & 48 Orang \\
\hline
\end{tabular}

Agar pelaksanakan penelitian dapat berjalan dengan lancar sesuai yang diharapkan, maka ada beberapa rancangan yang penleiti lakukan diantaranya : (1) latihan dilakukan sebanyak 16 kali pertemuan, dilakukan sebanyak 3 kali dalam 1 minggu. Jadwal latihan hari rabu, jumat dan minggu dimulai jam 16.00-18.00. Durasi pemanasan 20 menit, inti 60-80 menit dan pendinginan selama 20 menit, (Ricky, 2020)

Pengumpulan data menggunakan intrumen tes smash diagonal dan smash frontal. Pengujian data dengan menguji normalitas dan homogenitas. Normalitas data memakai uji Lilliefors (Iqbal \& Gushendra, 2016). Tujuan uji normalitas untuk melihat sampel apakah tesebar secara normal. Lalu dilanjutkan dengan uji homegenitas untuk melihat apakah sampel memiliki kemampuan yang tidak jauh berbeda atau sama.Setelah itu dilakukan uji hipotesis. Apabila hasil analisis varians menunjukkan adanya pengaruh utama (main effect) antara variabel bebas terhadap variabel terikat dan adanya interaksi (simple effect) variabel bebas terhadap variabel terikat maka dilanjutkan dengan uji Tuckey sebagai uji lanjut 
untuk menentukan kelompok mana yang memiliki hasil kemampuan smash pada taraf signifikansi $\alpha=0,05$.

\section{HASIL DAN PEMBAHASAN}

Penelitian ini menggunakan 2 variabel, variabel terikatnya yaitu kemampuan smash dalam bola voli sedangkan variabel bebasnya adalah latihan box drill. Hasil smash bolavoli yang digunakan untuk analisis berupa data hasil standar skor antara sasaran dari 10 kali smash bolavoli yaitu 5 kali smash diagonal dan 5 kali smash frontal oleh pemain yang mengikuti latihan, baik dengan latihan box drill. Dari hasil smash yang diambil dari tes awal dan tes akhir guna mencari data dari latihan yang dilakukan. Hasil kemampuan smash tersebut diolah setelah dilakukan perlakuan.

\section{Tes Awal Smash bola voli sebelum perlakuan}

Berdasarkan dari hasil tes awal kemampuan smash dari 32 orang pemain bola voli SMA Negeri 1 Baso sebelum dilakukan perlakuan box drill dipoleh mean atau rata-rata 14,688, standar deviasinya adalah 2,1468, kemudian diporoleh skor tertinggi 18 dan skor terendah adalah 9 angka. Sedangkan jarak pengukurannya adalah 9 , selengkapnya dapat dilihat pada tabel di bawah ini :

Tabel 2. Distribusi Data Hasil Tes Awal sebelum dilakukan treatment

\begin{tabular}{cccc} 
No & $\begin{array}{c}\text { Kelas } \\
\text { Interval }\end{array}$ & $\begin{array}{c}\text { Frekuensi } \\
\text { Absolut }\end{array}$ & $\begin{array}{c}\text { Frekuensi } \\
\text { Relatif }\end{array}$ \\
\hline 1 & $09-10$ & 2 & 6,25 \\
2 & $11-12$ & 3 & 9,37 \\
3 & $13-14$ & 7 & 21,87 \\
4 & $15-16$ & 13 & 40,62 \\
5 & $17-18$ & 7 & 21,87 \\
& & 32 & 100 \\
\hline
\end{tabular}

Berpedoman pada tabel 2, maka didapatkan hasil dari 32 orang siswa SMAN 1 Baso, dengan kelas interval 09-10 adalah 2 orang (6,25\%), untuk kelas interval 11-12 adalah 3 orang (21,87), 13-14 adalah 7 orang, 15-16 adalah 13 orang, 17-18 adalah 7 orang, , untuk lebih jelasnya dapat di lihat pada diagram: 


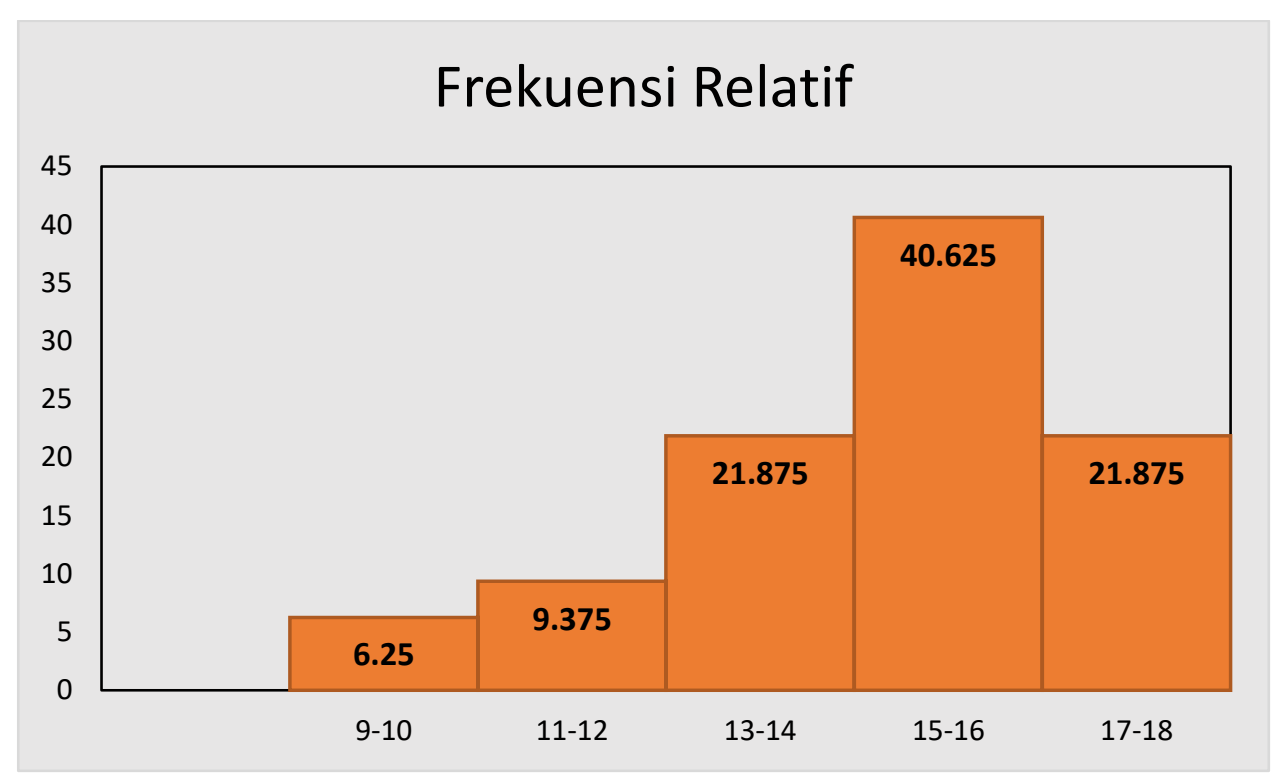

Gambar 1. Diagram kemampuan smash bola voli sebelum dilakukan perlakuan box drill

\section{Tes Akhir kemampuan smash sesudah dilakukan perlakuan}

Berdasarkan dari hasil tes akhir kemampuan smash 32 orang pemain bola voli SMA Negeri 1 Baso sesudah dilakukan perlakuan box drill dipoleh mean atau rata-rata 17,43, standar deviasinya adalah 2,66, kemudian diporoleh skor tertinggi 22 dan skor terendah adalah 11 angka. Sedangkan jarak pengukurannya adalah 9, selengkapnya dapat dilihat pada tabel di bawah ini :

Tabel 3. Distribusi Data Hasil Tes Akhir sesudah dilakukan treatment

\begin{tabular}{cccc}
\hline No & $\begin{array}{c}\text { Kelas } \\
\text { Interval }\end{array}$ & $\begin{array}{c}\text { Frekuensi } \\
\text { Absolut }\end{array}$ & Frekuensi Relatif \\
\hline 1 & $11-12$ & 2 & 6,25 \\
2 & $13-14$ & 2 & 6,25 \\
3 & $15-16$ & 6 & 18,75 \\
4 & $17-18$ & 12 & 37,5 \\
5 & $19-20$ & 4 & 12,5 \\
6 & $21-22$ & 6 & 18,75 \\
& & 32 & 100 \\
\hline
\end{tabular}

Berpedoman pada tabel 3, dari 32 orang pemain bola voli SMAN 1 Baso yang memiliki kelas interval 11-12 adalah 2 orang (6,25\%), 13-14 adalah 2 orang 
(6,25), 15-16 adalah 6 orang, 17-18 adalah 12 orang, 19-20 adalah 4 orang, 21-22 adalah 6 orang, untuk lebih jelasnya dapat di lihat pada diagram di bawah ini:

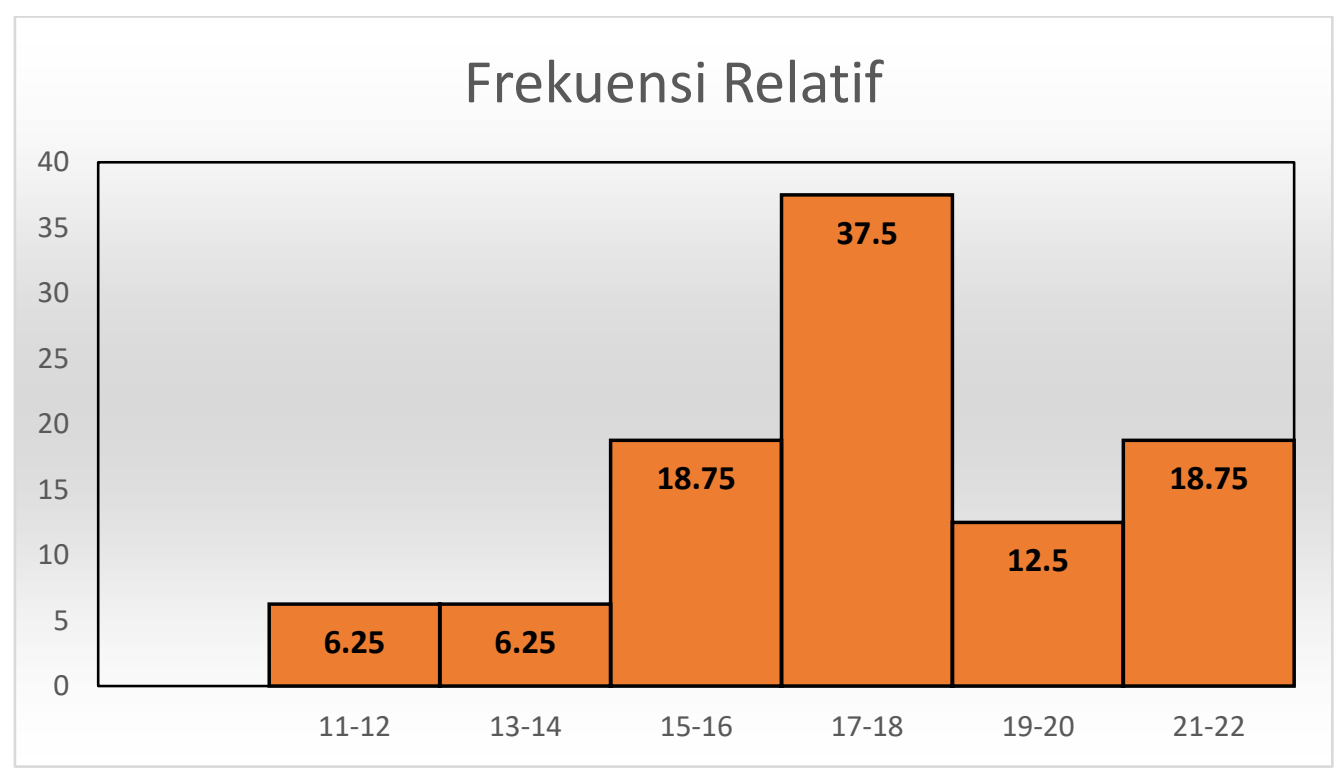

Gambar 2. Diagram kemampuan smash bola voli setalah diberi perlakuan

\section{Uji Persyaratan Analisis}

\section{Pengujian Normalitas}

Penelitian ini terlebih dahulu dilakukan uji analisis dengan uji normalitas data guna melihat data dari variabel yang diteliti berdistribusi normal atau tidak, dapat digunakan dengan uji lilifors dengan taraf signifikansi $\alpha=0,05$

H0 : Lo $<$ Lt data normal

Ha : Lo > Lt data tidak normal

Ringkasan hasil uji normalitas sampel pemain bola voli SMAN 1 Baso Kabupaten Agam :

Tabel 4. Uji Normalitas

\begin{tabular}{llll}
\hline \multicolumn{1}{c}{ Variabel } & Lobservas & Ltabel & \multicolumn{1}{c}{ Kesimpula } \\
\hline $\begin{array}{l}\text { Latihan box drill terhadap } \\
\text { kemampuan smash bola voli }\end{array}$ & 0,115 & 0,227 & Normal \\
\hline
\end{tabular}


Berdasarkan tabel, uji Lilifors yaitu Lo $<$ Lt $\alpha=0,05$, jika Lo lebih kecil dari Lt, dengan demikian kedua variabel berditribusi normal.

\section{Pengujian Homogenitas}

Uji Homogenitas di analisis dengan statistik uji F dengan menggunakan derajat kebebasan dan taraf signifikansi 0,05 pada distribusi F. Rangkuman hasil uji Homogenitas Varians:

Tabel 5. Rangkuman Uji Homogenitas Data

\begin{tabular}{ccc}
\hline F hitung & F tabel & Keterangan \\
\hline 0,93 & 2,51 & Homogen \\
\hline
\end{tabular}

Karena Fhitung < Ftabel, dapat disimpulkan bahwa kelompok sampel ini homogen.

\section{Pengujian Hipotesis}

Hipotesis penelitian ini yaitu latihan box drill berpengaruh kepada kemampuan smash bola voli. Hasil dari pengujian hipotesis ternyata latihan box drill memberi dampak berarti terhadap kemampuan smash pemain bola voli SMA Negeri 1 Baso.

Tabel 6. Uji beda Pretest dan Posttest kemampuan smash bola voli

\begin{tabular}{cccc}
\hline df & t hitung & t tabel & Kesimpulan \\
\hline 31 & 13.04 & 2,040 & Signifikan \\
\hline
\end{tabular}

Dari tabel di atas ditemukan t hitung 13,04 > 2,040. Maka kesimpulannya adalah latihan box drill berpengaruh signifikan terhadap kemampuan smash bola voli.

\section{KESIMPULAN}

Terdapat pengaruh antara latihan box drill dengan smash dalam bola voli pada siswa yang melakukan kegiatan bola voli SMAN 1 Baso Kabupaten Agam. Hasil pembahasan latihan box drill terhadap kemampuan smash dalam bola voli 
didapatkanf hitung $>\mathrm{f}_{\text {tabel}}$, sehingga $\mathrm{h}_{0}$ ditolak. Dan $\mathrm{h}_{1}$ diterima, terdapat pengaruh latihan box drill terhadap kemampuan smash dalam bola voli.

Nilai pada smash yang dilakukan pada perlakuan latihan box drill sangat tinggi pada siswa SMA Negeri 1 Baso Kabupaten Agam yang mengikuti latihan yaitu siswa putera. Latihan ini memilki intensitas yang berat karena menggunakan alat sebagai bantuan pada saat latihan. Bagi pamain yang memiliki kemauan kuat, hal ini bedampak pada hasil yang akan didapatkan yaitu peningkatan smash dalam olahraga bola voli. Dari analisis yang sudah dilakukan maka dapat ditarik suatu kesi pulan bahwa Latihan box drill berpengaruh terhadap kemampuan smash bola voli.

\section{DAFTAR PUSTAKA}

Iqbal, R., \& Gushendra, W. (2016). Perbedaan Pengaruh Latihan Pliometrik dan Skipping Terhadap Power Otot Tungkai Pada Pemain Bola Basket. Jurnal Ilmiah PENJAS, 2(2), 57-76.

Nur, M., Hidayah, T., Artikel, S., korespondensi, A., Mayjend Sutoyo, J., \& Tengah, J. (2017). Journal of Physical Education and Sports Pengaruh Metode Latihan dan Power Otot Tungkai terhadap Kelincahan. 279 JPES.

Pranopik, M. R. (2017). Pengembangan Variasi Latihan Smash Bola Voli. Jurnal Prestasi, 1(1), 31-33.

Radcliffe, J. (2013). Functional Training For Athletes At All Levels (L. Chou, ed.). United States: United States by Ulysses Press.

Ricky, Z. (2020). Studi Eksperimen Pengaruh Latihan Jump In Place Terhadap Kemampuan Smash Bola Voli. Jurnal Jendela Olahraga Universitas PGRI Semarang, 05(02), 150-159.

Sarjono \& Sumarto. (2010). Pendidikan Jasmani, Olahraga dan Kesehatan. CV Aneka Ilmu.

Sole, C. J. (2018). Plyometric training. In Advanced Strength and Conditioning. https://doi.org/10.4324/9781315542348-16.

Stojanović, E., Ristić, V., McMaster, D. T., \& Milanović, Z. (2016). Effect of Plyometric Training on Vertical Jump Performance in Female Athletes: A Systematic Review and Meta-Analysis. Sports Medicine, 47(5), 975-986. 
https://doi.org/10.1007/s40279-016-0634-6.

Sugarwanto, S., \& Okilanda, A. (2020). Pengaruh Latihan Single Leg Hops Terhadap Hasil Lompat Jangkit Siswa SMP 1 Sungai Lilin. Kinestetik. https://doi.org/10.33369/jk.v4i1.10472.

Sugiyono. (2016). Metode Penelitian, Kuantitatif, Kualitatif dan $R \& D$. Bandung: Alfabeta.

Syafruddin. (2011). Ilmu Kepelatihan Olahraga. Padang: UNP Press.

Winarno, D. (2013). Teknik Dasar Bermain Bola Voli. Malang: Jurusan Pendidikan Jasmani dan Kesehatan FIK Malang. 